\title{
Cytological Sub-Classification of Atypia of Undetermined Significance May Predict Malignancy Risk in Thyroid Nodules
}

\author{
Abdulghani Elomami $^{\mathrm{a}}$ Shahad Abobakr Elhag ${ }^{\mathrm{b}} \quad$ Eiman Alseddeeqi $^{\mathrm{c}}$ \\ aDivision of Anatomy Pathology and Cytopathology, Tawam Hospital, Al Ain, United Arab Emirates; \\ ${ }^{b}$ Education Institute, Sheikh Khalifa Medical City, Abu Dhabi, United Arab Emirates; 'Division of Endocrinology, \\ Sheikh Khalifa Medical City, Abu Dhabi, United Arab Emirates
}

\section{Keywords}

Atypia/follicular lesion of undetermined significance ·

Thyroid FNA · Thyroid cancer · Bethesda category III · Atypia sub-classification

\section{Abstract}

Background: Atypia/follicular lesion of undetermined significance (AUS/FLUS) carries a malignancy risk reaching up to $50 \%$. Based on the reported malignancy rate in a given population, the clinical practice towards such a category varies. We hereby identify clinical parameters for risk stratification to aid in decision-making for either surgical referral or a clinical follow-up. Our aim is to identify clinical parameters that guided both clinicians and patients at our institutions to reach a clinical decision including atypia types. Methods: $\mathrm{A}$ retrospective review of patients with Bethesda III category thyroid nodules from tertiary centres in the Emirate of Abu Dhabi during January 2011 through December 2015 was carried out. Malignancy risk in Bethesda category III nodules and repeat FNA utility were calculated. Parameters that guided both clinicians and patients for appropriate referral to surgery were studied. Results: Two hundred and two cases were included in the study. Of these, 101 cases underwent surgery initially following the first FNA and 10 cases following FNA repeat. Histology confirmed malignancy in (41\%) of cases that went initially to surgery and in (40\%) of cases that underwent a repeat FNA. Repeat FNA resulted in 17 (44.74\%) cases being re-classified into benign category, 10 (26.3\%) being AUS/FLUS category, 6 (15.7\%) being both suspicious and malignant, and 5 (13.16\%) being unsatisfactory. Repeating FNA resulted in a definitive diagnostic utility in $50 \%$ of the cases. Eighty percent of malignant cases demonstrated nuclear atypia. Conclusion: The relatively high malignancy rate in our institutions, the suspicious radiographic features, the atypia groups, and the repeat FNA predictive value stratified Bethesda III category nodules for proper malignancy prediction and appropriate management.

(C) 2021 The Author(s)

Published by S. Karger AG, Base

\section{Introduction}

Bethesda III category thyroid nodules, which include atypia or follicular lesion of undetermined significance (AUS/FLUS), have a 5-15\% risk for thyroid malignancy $[1,2]$. The Bethesda system was introduced to establish diagnostic categories for thyroid aspirates and to imply karger@karger.com www.karger.com/acy

Karger $\stackrel{\text { ' }}{=}$

GOPEN ACCESS
(C) 2021 The Author(s)

Published by S. Karger AG, Basel

This is an Open Access article licensed under the Creative Commons Attribution-NonCommercial-4.0 International License (CC BY-NC) (http://www.karger.com/Services/OpenAccessLicense), applicable to the online version of the article only. Usage and distribution for commercial purposes requires written permission.
Abdulghani Elomami

Division of Anatomy Pathology and Cytopathology

Tawam Hospital

PO Box 15258, Al Ain (United Arab Emirates)

aelomami@seha.ae 
malignancy risks for clinical management recommendations [3]. Therefore, the recommended guideline for the initial management of AUS/FLUS is a clinical follow-up by repeating FNA in $\geq 3$ months based on the risk of thyroid malignancy in a given population [4]. Repeating fine needle aspiration resulted in re-classification of $70 \%$ of Bethesda III samples into Bethesda II category [5]. The utility of repeating FNA for category III was therefore an auxiliary tool for clinical decision-making. Bethesda III category nodules remained a similar category in up to $31 \%$ of cases [6]. Repeating an FNA results in a cost-effective practice by avoiding unnecessary diagnostic surgery. If other studies are appraised, one would find varying reported rates of malignancy risks ranging from 2 to $50 \%$ which will dictate the clinical practice; that is, repeating an FNA versus referring to surgery [4, 7-12].

Two meta-analyses concluded higher malignancy rates than that reported by the Bethesda $[13,14]$. Possible reasons for this discrepancy include differences in patients' demographics, technical issues which include the adequacy of the sampled material, the optimization of cellular preservation and slide preparation, and the level of comfort/expertise of the reporting pathologist. Molecular markers testing has been recommended by the American Thyroid Association to provide a pretest probability for Bethesda III nodules. The results of such testing provide guidance regarding whether to repeat a biopsy or to refer to surgery [15].

The rate of malignancy for Bethesda III category in a given population is an essential fact to delineate the next step of management. There is no uniform practice in the Emirate of Abu Dhabi towards such a category as there is little known regarding thyroid cancer behaviour in the UAE population.

The American Thyroid Association recognizes that the prevalence of malignancy for the indeterminate categories varies substantially among centres, and states that: "it is crucial to know the prevalence of malignancy within each indeterminate cytological category at one's institution." Based on that statement, our study results can provide a recommendation regarding managing thyroid nodules with Bethesda III category and assist in counselling patients to reach a decision at our institutions [15]. A similar commentary in Thyroid states the same principle: "It is crucial to know the incidence of malignancy in each of the Bethesda categories in one's own institution in order to make reasonable treatment decisions" [16]. The McGill Thyroid Nodule Score has served as a predictor tool for malignancy in thyroid nodules [17]. A study published in 2015 has studied that clinical tool to evaluate the incidence of malignancy in indeterminate nodules preoperatively [18].

Many institutions have proposed that the malignancy rate in nuclear atypia is higher than that seen in samples with architectural atypia. A similar study conducted in Singapore concluded that samples reported as cytological atypia on FNA had a malignancy rate of $36.8 \%$ in comparison to a rate of $14.7 \%$ in samples reported initially as architectural atypia on cytological analysis [19]. Moreover, a meta-analysis by Ahn et al. [20] reported that the overall malignancy rate in cytological atypia (24.3-65.8\%) was significantly high when compared to that reported in samples with architectural atypia (5.95-38.8\%).

Therefore, we chose to address factors that risk stratify the Bethesda III category nodules in order to aid in clinical decision, that is, referral to surgery versus repeat an FNA at our centres. Our objectives are to calculate the malignancy rate, predict malignancy rate based on atypia grouping, examine the medical practice towards such a category, and predict the clinical utility of repeating an FNA.

\section{Method}

Study Settings and Participants

This is a retrospective medical records review of patients with Bethesda III category nodules from 3 tertiary centres in the Emirate of Abu Dhabi. All Bethesda III category cases that were diagnosed from January 2011 through December 2015 were extracted from the electronic pathology database. The database identified 240 patients above 14 years of age of which 38 patients other than Bethesda III category were excluded. The fine needle aspiration biopsy was carried out under ultrasound guidance. The diagnosis of Bethesda III category was made by different certified pathologists at the 3 different institutions. The total number of patients ended up being included in the study was 202. An institutional research board approval was obtained from each institution.

\section{Study Variables}

Information on patients' gender, age at time of fine needle aspiration procedure was extracted from the electronic medical records. Age was categorized into 3 groups: younger than 40 years old, 40-64 years old, and 65 and above years old. Clinical management of the Bethesda III category cases was recorded and it included one of the followings: diagnostic surgery or follow-up with either a repeat FNA (in $3+$ months from the first one) or an ultrasound (in $6+$ months). Surgery was either a thyroid lobectomy or a total thyroidectomy. Forty-nine cases had no follow-ups or surgery as an initial management. Patients with no follow-ups included patients who visited other medical institutions in the same city to have a second opinion, those who travelled elsewhere for a second opinion, and a portion whom we did not have any date about. Fourteen patients chose follow-up with US despite recommendations for either surgery or an FNA repeat. The US was performed 
a year from the last FNA and demonstrated no increase in nodule size (a significant growth was defined as a growth of $>20 \%$ increase in 2 nodule dimensions or $>50 \%$ increase in the volume). The clinical follow-up included follow-up with an US. A major indication for surgery was the presence of suspicious features on ultrasound. Patients' preferences were another indicator explaining such a high rate for surgical referrals. Radiation exposure and a positive family history for thyroid malignancy were other indicators for referring to surgery at our institutions.

A certified general pathologist diagnosed cases of Bethesda III category based on adequate number of thyroid follicles on FNA smears. Hospital onsite adequacy assessment was performed by a cytology screener, who performed slides preparation. Conventional air dried and alcohol fixed smears were prepared and subject to Diff-Quik and Papanicolaou stains respectively. Diagnosing Bethesda III category was based on the 2007 National Cancer Institute Thyroid fine needle aspiration state of the science conference criteria $[1,15]$. Different certified pathologists reported the interpretation at different sites. They have all used the same criteria (2007 National Cancer Institute Thyroid fine needle aspiration state of the science conference criteria) among the 3 different institutions in order to minimize interobserver bias and assessment. All cellularities were adequate. In case of inadequacy, the category falls into a Bethesda I category where an FNA is repeated.

Following up by either an ultrasound or an FNA repeat was proposed if there were no suspicious ultrasonographic features such as calcifications and a nodule appearing taller that wide. On some occasions, patients' preferences were guiding the clinical decision. The repeat FNA was performed 3 months or more from the initial FNA.

Atypia was classified into 2 categories: either nuclear/cytological versus architectural atypia. Both benign and malignant cases were correlated with percentage of associated atypia sub-classification.

Nuclear atypia was defined as mild nuclear enlargement, membrane irregularities such as wrinkles or grooves, overlapping, or chromatin clearing. While specimens with low cellularity, absent or minimal colloid, and micro-follicles (including those with oncocytic changes) were defined as architectural atypia.

\section{Statistical Analysis}

The malignancy rate was calculated for nodules that underwent thyroid lobectomy or total thyroidectomy. Those without followup were not included in the analyses of malignancy risk calculation. Descriptive statistics were represented in tables. Data were tabulated and analysed, and figures were made using Microsoft Excel version 15.33.

\section{Result}

Two hundred and two cases out of all thyroid FNAs performed during 2011-2015 were diagnosed as AUS/ FLUS (Fig. 1). Of these, 166 (82.2\%) were women and 36 (17.8\%) were men. The age of the patients ranged from 14 to 84 years with median age of 47 years (Table 1 ). Fourteen patients had follow-ups with ultrasound. Forty-nine

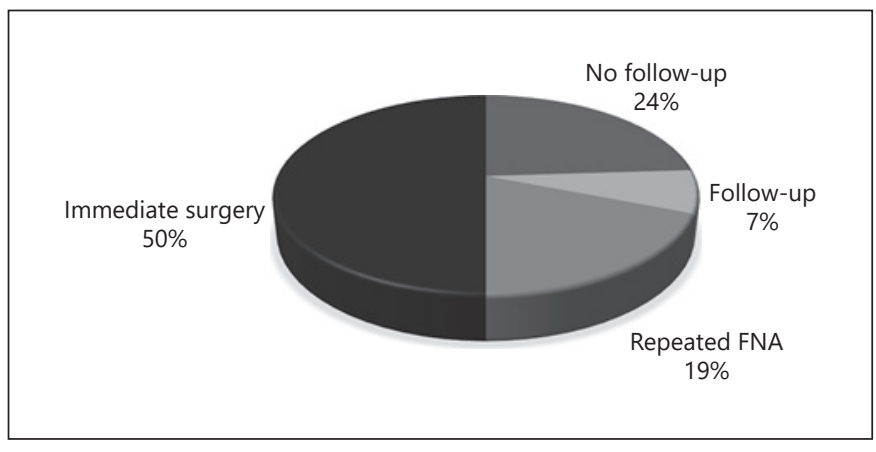

Fig. 1. Total number of patients with AUS diagnosis and management. AUS, atypia of undetermined significance.

Table 1. Baseline demographics of patients

\begin{tabular}{lllr}
\hline & $\begin{array}{l}\text { Tawam } \\
\text { Hospital }\end{array}$ & $\begin{array}{l}\text { Sheikh Khalifa Medical } \\
\text { City and Mafraq Hospital }\end{array}$ & Total \\
\hline Male & 18 & 18 & 36 \\
Female & 98 & 68 & 166 \\
$<40$ years & 34 & 20 & 54 \\
$40-64$ years & 73 & 56 & 129 \\
$\geq 65$ years & 49 & 10 & 19 \\
\hline
\end{tabular}

patients did not have any follow-up. One hundred and eleven out of 202 patients with AUS/FLUS category underwent surgery, 101 immediately after the first FNA, and 10 following the repeated FNA (Fig. 2). One hundred and one patients $(50 \%)$ underwent immediate surgery. Their histology confirmed 42 malignant (41\%) cases and 59 benign (59\%) cases. Thirty-eight out of the 202 patients (18.8\%) underwent a repeat FNA procedure. The repeat procedure resulted in 17 (44.74\%) cases being re-categorized as benign, $10(26.3 \%)$ as AUS/FLUS, $6(15.7 \%)$ as both suspicious and malignant, and $5(13.16 \%)$ as unsatisfactory (Fig. 3). Ten cases from the repeat FNA group underwent surgery. Three out of 4 suspicious cases and 1 out of 2 malignant cases confirmed to be malignant following surgery (40\%). The repeat FNA resulted in definitive diagnostic utility for $50 \%$ of the cases; $44.74 \%$ of the nodules were re-classified into Bethesda II category upon FNA repeat.

Forty-six cases confirmed malignancy on histology. Out of these, 35 cases were of papillary carcinoma type and 9 were of follicular carcinoma type (Table 2; Fig. 4). Upon cytological examination, we found that 37 out of the 46 malignant cases (80\%) were reported as cytological/ nuclear atypia, of which 35 were of papillary carcinoma 


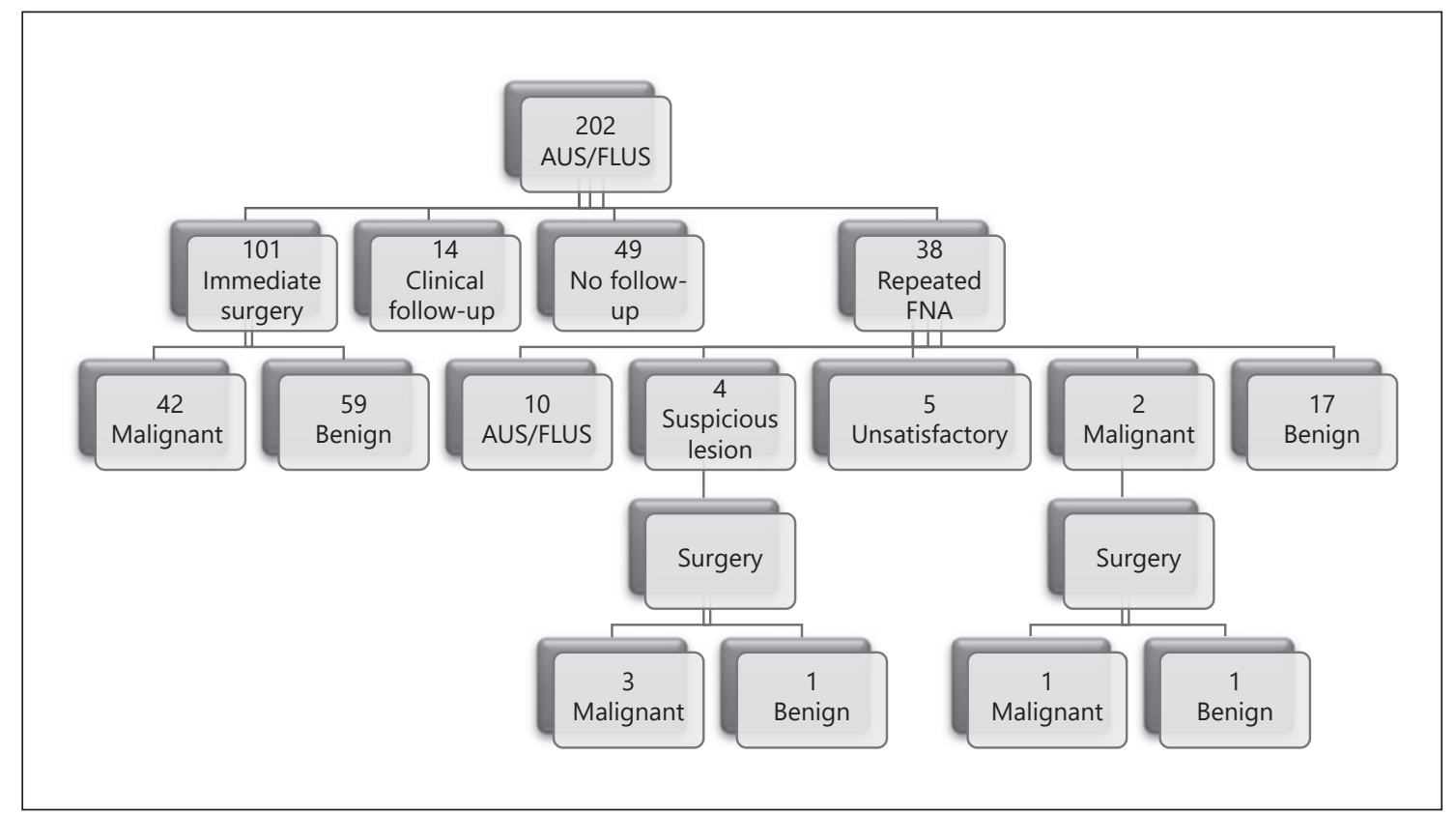

Fig. 2. Number of patients with AUS \& management outcomes. AUS, atypia of undetermined significance; FLUS, follicular lesion of undetermined significance.

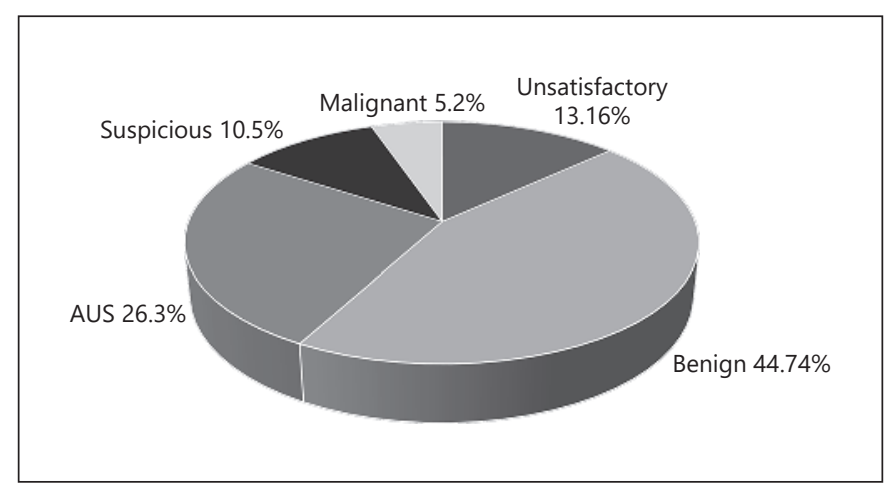

Fig. 3. Diagnosis of repeated FNA cases.

type. On the other side, $19.5 \%$ of malignant cases demonstrated architectural atypia and it was of follicular carcinoma type. Seven out of 35 cases (20\%) of papillary thyroid cancer were of follicular variant type which did not demonstrate any nuclear or cellular atypia (Table 3; Fig. 5).

Of the 65 benign cases, histological examination from $76.9 \%$ (50 patients) showed MNG with hyperplastic nodule (40 samples) or follicular adenoma (10 samples) as the most common pathology. Those types of histological findings demonstrated architectural atypia on cytological analysis.

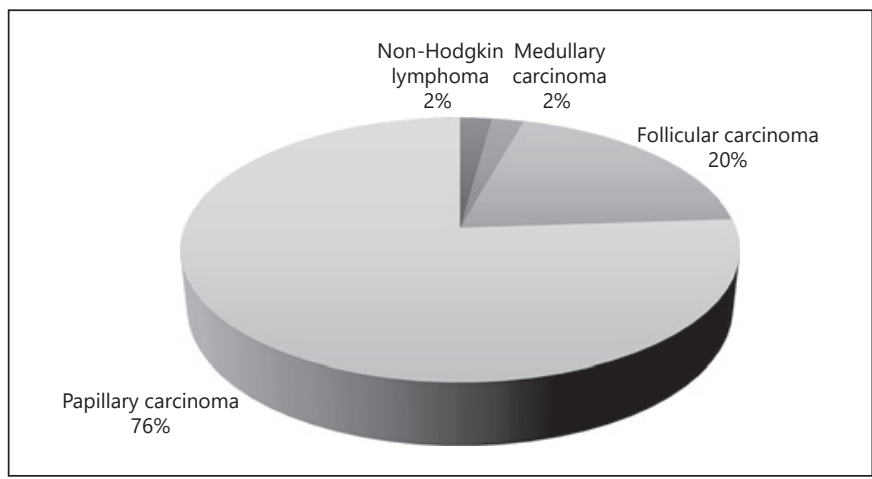

Fig. 4. The malignant histological subtypes of the AUS (Bethesda group III) cases. AUS, atypia of undetermined significance.

\section{Discussion}

The reported malignancy risk in Bethesda III category varies among different institutions. Factors including inter- and intraobserver variability of reporting among pathologists affect that variation [21].

In our study, the overall number of cases with Bethesda III category was 202 cases amongst all biopsies performed during the 5-year period. Our malignancy rate is $41 \%$ for cases that underwent surgery initially and $40 \%$ for cases that underwent surgery following a repeat FNA. 
Table 2. Reported malignant variants

\begin{tabular}{|c|c|c|c|c|c|c|}
\hline Tumour & Papillary carcinoma & Other & FC & Anaplastic & Medullary & Total \\
\hline Tawam & 20 (1 follicular variant and 1 oncocytic variant) & $1 \mathrm{NHL}$ & 9 & 0 & 1 & 31 \\
\hline SKMC & $15(6 \mathrm{FV}-\mathrm{PTC})$ & 0 & 0 & 0 & 0 & 15 \\
\hline Total & 35 & 1 & 9 & 0 & 1 & 46 \\
\hline
\end{tabular}

Table 3. Reported benign variants

\begin{tabular}{lllllll}
\hline Tumour & Hashimoto's & $\begin{array}{l}\text { Hurthle cell } \\
\text { adenoma }\end{array}$ & $\begin{array}{l}\text { MNG with } \\
\text { hyperplastic nodule }\end{array}$ & $\begin{array}{l}\text { Follicular } \\
\text { adenoma }\end{array}$ & Granulomatous & Total \\
\hline Tawam & 7 & 2 & 23 & 8 & 2 & 42 \\
SKMC & 2 & 2 & 17 & 2 & 0 & 23 \\
\hline Total & 9 & 4 & 40 & 10 & 2 & 65 \\
\hline
\end{tabular}

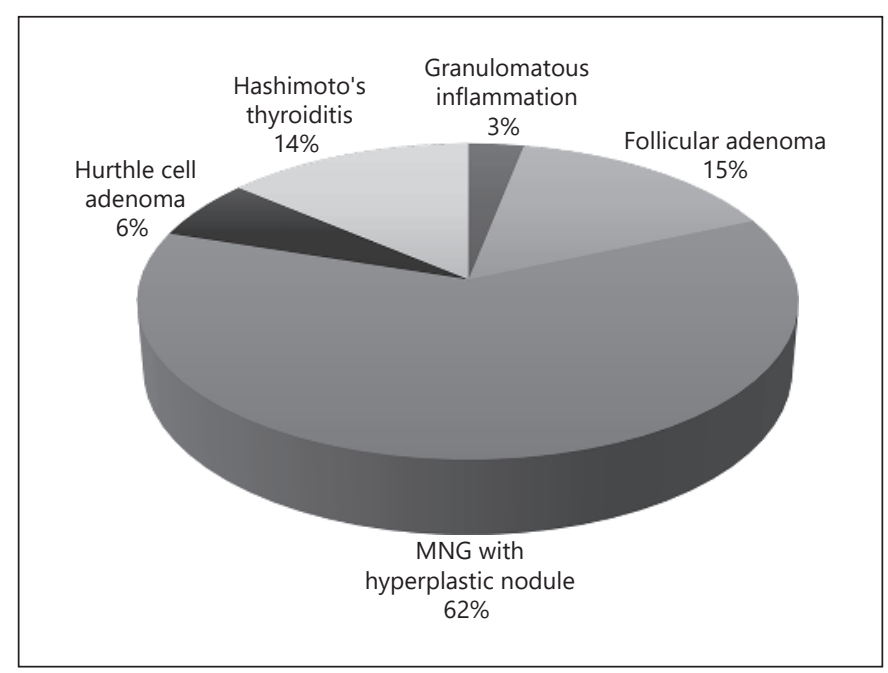

Fig. 5. The benign histological subtypes of the AUS (Bethesda group III) cases. AUS, atypia of undetermined significance.

This is a significantly higher rate than that reported by the Bethesda. A similar study performed in our city published in 2018 concluded a lower rate which was $20 \%$ [22]. Since only $50 \%$ of patients underwent surgery, it is possible that the true malignancy rate in AUS/FLUS nodules is just slightly above $20 \%$. Still that higher risk is explained by the fact that our 3 institutions are tertiary centres and probably higher risk patients are being referred to. Globally the incidence of thyroid cancer is rising [23]. In UAE, thyroid cancer is the second most common malignancy amongst females [24]. On the same note, a study con- ducted by Alseddeeqi et al. [25] concluded a high malignancy rate among all thyroid nodules in the UAE. Patient's genetics make up and the nature of the lifestyle in our region might have played a role in such a finding. A more precise guidance to assessment and decision-making can be accomplished through applying molecular testing which aids in avoiding unnecessary surgical risks and costs [26].

Ozluk et al. [27] reported a lower malignancy rate (36\%) compared to ours in their study of 3,444 nodules. Ho et al. [28] reported malignancy rate that is also lower compared to ours $(37.8 \%)$ in their population who presented to a tertiary cancer centre where a referral bias could have existed. A retrospective analysis by Lee et al. [29] involving 4,933 aspirates was consistent with our malignancy rate $(41.2 \%)$ in their Bethesda III category cases. The malignancy rate in our institutions is a fact clinicians can base their decisions on along with the following parameters: the clinical presentation, ultrasonographic characteristics, and nuclear features [30].

The recommendation for AUS/FLUS results category is a repeat FNA in 3 months. Fifty percent of our AUS/ FLUS cases underwent surgery following the first FNA. A major indication for surgery was the presence of suspicious features on ultrasound. Patients' preferences were another indicator explaining such a high rate for surgical referrals. Compared to another study, the percentage of cases that underwent surgery initially was $61 \%$, a rate which is higher than ours. That study's major cause for surgical referral was the presence of suspicious features on ultrasound [22]. Therefore, the rate of ma- 
lignancy in a given institution, the clinical presentation, and nuclear features need to be considered along with the US findings when calculating the pretest probability in AUS/FLUS cases [14]. Radiation exposure and a positive family history for thyroid malignancy were other indicators for referring to surgery at our institution. The relatively affordable cost for surgery by the insuring agent in our institutions was in favour of recommending surgery over implementing a costly molecular markers assessment.

FNA repeat provided a definitive diagnosis in only $50 \%$ of the cases according to our study. This result is of value for patients as they are involved in the decisionmaking. Our result provided a better utility than a study published by Allen et al. [31] where the repeat FNA procedure provided a $40 \%$ definitive diagnosis. Yet our utility rate is not considered to be of guidance to clinicians and patients for the decision-making. Our malignancy rate in cases that underwent surgery initially is similar to that in cases that underwent surgery following a repeat FNA. That finding is similar to the one found by Vanderlaan et al. [32] where their AUS/FLUS cases demonstrated similar malignancy rate following initial and repeat FNA.

Based on our malignancy rate, the availability and the cost of surgery, the presence of suspicious features on US or a positive clinical indicator, surgery was favoured as an option in our cohort. The utility of repeating an FNA was another factor that favoured referrals to surgery. Atypia sub-classification could aid in guiding further decision regarding referral to surgery.

Our study has identified malignant and benign nodules initially and then was followed by identifying type of atypia the nodule harbour. This approach is different from most studies in which they identified type of atypia initially and followed that with a correlation with either a benignity or a malignancy.

Sub-classification of Bethesda group III was discussed in more detail in the second edition of Bethesda classification published in 2017. Types of atypia presented were as follows: cellular, architectural, Hurthle cell atypia, and atypia otherwise not specified. In our study, we chose to correlate cellular and architectural with occurrence of malignancy as these 2 types were most correlated with malignancy occurrence as to produce clinically significant outcomes.

Eighty percent of our confirmed malignancy cases demonstrated features of cytological/nuclear atypia. This finding is slightly higher yet very similar to that reported by Eisa et al. [33] with a malignancy rate of $74 \%$ in sam- ples with nuclear/cytological atypia. Another study conducted by Huhtamella found that the rate of malignancy was almost the same for both nodules with architectural and cytological atypia, 12 and $12.4 \%$ respectively [34]. Among the malignant variants, papillary carcinoma was the most common diagnosis with a prevalence of $80.5 \%$ followed by NHL (1.5\%) and medullary carcinoma (1.5\%). On the other hand, the most common benign form was MNG with hyperplastic nodules seen in 40 cases (61.5\%) followed by follicular adenomas reported in 10 patients (15.4\%). Those findings are similar to those reported by Johnson et al. [35] with papillary carcinoma being the most common malignancy in both cytological and architectural atypia subgroups with a prevalence of 84.8 and $78.6 \%$ respectively. A similar study in Korea reported papillary carcinoma as the most common malignancy in the cytological atypia group (138 cases) followed by follicular variant ( 9 cases) [36].

The limitations in our study are that of any retrospective study design. We had 49 cases without follow-ups. More than 1 certified pathologist was involved in diagnosing AUS/FLUS category which could affect the rate of Bethesda III category diagnosis but that was somehow overcome by adhering to AUS/FLUS diagnostic criteria which kept equivocal results to a minimum. Since malignancy rates reported were only for nodules that underwent resection, following up the non-surgical nodules would rule out false negative results. Moreover, the false negative results could have been verified if surgery was performed on nodules with Bethesda II category. If those 14 cases with radiological follow-up were further studied at a longer time period (over a year), a true malignancy rate would have been estimated.

This is the first study of its kind in the region that addressed multiple factors to risk stratify Bethesda III category nodules. Our results definitely would guide clinicians and patients referred to our institutions to the next plan of management. The diagnostic utility for FNA repeat was a useful tool for patients to guide them for decision-making. A unique approach we undertook is that we identified the nature of the nodule first, that is, malignant versus benign then correlated type of atypia that nodule harbours.

We believe that our study makes a significant contribution to the care provided in our tertiary referral centres because it takes into consideration readily available clinical data for risk stratification. Based on the findings in our tertiary centres, we were able to properly refer those nodules to surgery. 


\section{Conclusion}

The relatively high malignancy rate in our institutions, the presence of suspicious radiographic features, and the FNA repeat predictive value guided both clinicians and patients for appropriate referrals to surgery. Malignancy risk could also be more predicted based on atypia subclassification.

\section{Statement of Ethics}

Ethical approval was obtained from SKMC Institutional Review Board/Research Ethics Committee and Tawam Human Research Ethics Committee (T-HREC). Consent to participate is not applicable.

\section{Conflict of Interest Statement}

The authors have no conflicts of interest to declare.

\section{Funding Sources}

The study required no funding, and therefore it did not receive any forms of financial support.

\section{Author Contributions}

E.A., R.M., and A.E. contributed to the study design. R.M. and A.E. accomplished data collection. A.E. analysed the data. E.A., A.A., and Y.M. drafted different parts of the manuscript, and all approved the final version.

\section{Availability of Data and Material}

As the database included in this study is de-identified, it is not available in an open access repository. Supporting data can be requested by emailing the corresponding author.

\section{Disclosure}

The article does not contain any studies with human or animal subjects performed by the any of the authors.

\section{References}

1 NCI Thyroid FNA State of the Science Conference; Cibas ES, Ali SZ. The Bethesda system for reporting thyroid cytopathology. Am J Clin Pathol. 2009;132:658-65.

2 Kayılıglu SI, Dinc T, Sozen I, Senol K, Katar K, Karabeyoglu M, et al. Thyroid nodules with atypia or follicular lesions of undetermined significance (AUS/FLUS): analysis of variables associated with outcome. Asian Pac J Cancer Prev. 2014;15(23):10307-11.

3 Liu X, Medici M, Kwong N, Angell TE, Marqusee E, Kim MI, et al. Bethesda categorization of thyroid nodule cytology and prediction of thyroid cancer type and prognosis. Thyroid. 2016 Feb;26(2):256-61.

4 Brandler TC, MS Aziz MS, Coutsouvelis C, Rosen L, Rafael OC, Souza F, et al. Young investigator challenge: atypia of undetermined significance in thyroid FNA: standardized terminology without standardized management: a closer look at repeat FNA and quality measures. Cancer Cytopathol. 2016 Jan;124(1):37-43.

5 Erivwo P, Ghosh C. Atypia of undetermined significance in thyroid fine-needle aspirations: follow-up and outcome experience in Newfoundland, Canada. Acta Cytol. 2018; 62(2):85-92.

$6 \mathrm{Na}$ DG, Kim JH, Sung JY, Baek JH, Jung KC, Lee $\mathrm{H}$, et al. Core-needle biopsy is more useful than repeat fine-needle aspiration in thyroid nodules read as nondiagnostic or atypia of undetermined significance by the Bethesda system for reporting thyroid cytopathology. Thyroid. 2012;22(5):468-75.
7 Bongiovanni M, Krane JF, Cibas ES, Faquin WC. The atypical thyroid fine needle aspiration: past, present and future. Cancer Cytopathol. 2012;120:73-86.

8 Kholova I, Ludvikova M. Thyroid atypia of undetermined significance or follicular lesion of undetermined significance: an indispensable Bethesda 2010 diagnostic category or waste garbage? Acta Cytol. 2014;58:319-29.

9 Gan TRX, Nga ME, Lum JHY, Wong WM, Tan WB, Parameswaran R, et al. Thyroid cytology: nuclear versus architectural atypia within the "atypia of undetermined significance/ follicular lesion of undetermined significance" Bethesda category have significantly different rates of malignancy. Cancer Cytopathol. 2017 Apr;125(4):245-56.

10 Park HJ, Moon JH, Yom CK, Kim KH, Choi JY, Choi SI, et al. Thyroid "atypia of undetermined significance" with nuclear atypia has high rates of malignancy and BRAF mutation. Cancer Cytopathol. 2014 Jul;122(7): 512-20.

11 Sullivan PS, Hirschowitz SL, Fung PC, Apple SK. The impact of atypia/follicular lesion of undetermined significance and repeat fineneedle aspiration: 5 years before and after implementation of the Bethesda system. Cancer Cytopathol. 2014 Dec;122(12):866-72.

12 Kim TH, Jeong DJ, Hahn SY, Shin JH, Oh YL, $\mathrm{Ki} C S$, et al. Triage of patients with AUS/FLUS on thyroid cytopathology: effectiveness of the multimodal diagnostic techniques. Cancer Med. 2016;5(5):769-77.
13 Krauss EA, Mahon M, Fede JM, Zhang L. Application of the Bethesda classification for thyroid fine-needle aspiration: institutional experience and meta-analysis. Arch Pathol Lab Med. 2016 Oct;140(10):1121-31.

14 Valderrabano P, Khazai L, Thompson ZJ, Leon ME, Otto KJ, Hallanger-Johnson JE, et al. Cancer risk stratification of indeterminate thyroid nodules: a cytological approach. Thyroid. 2017 Oct;27(10):1277-84.

15 Haugen BR, Alexander EK, Bible KC, Doherty GM, Mandel SJ, Nikiforov YE, et al. American thyroid association management guidelines for adult patients with thyroid nodules and differentiated thyroid cancer: the american thyroid association guidelines task force on thyroid nodules and differentiated thyroid cancer. Thyroid. 2016 Jan;26(1):1-133.

16 Ho AS, Sarti EE, Jain KS, Wang H, Nixon IJ, Shaha AR, et al. Malignancy rate in thyroid nodules classified as Bethesda category III (AUS/FLUS): is there a correct answer? Thyroid. 2014 May 1;24(5):832-9.

17 Sands NB, Karls S, Amir A, Tamilia M, Gologan O, Rochon L, et al. McGill Thyroid Nodule Score (MTNS): "rating the risk," a novel predictive scheme for cancer risk determination. J Otolaryngol Head Neck Surg. 2011 Feb; 40(Suppl 1):S1-13.

18 Varshney R, Forest V-I, Mascarella MA, Zawawi F, Rochon L, Hier MP, et al. The Mcgill thyroid nodule score: does it help with indeterminate thyroid nodules? J Otolaryngol Head Neck Surg. 2015;44(1):2. 
19 Gan TR, Nga ME, Lum JH, Wong WM, Tan WB, Parameswaran R, et al. Thyroid cytology-nuclear versus architectural atypia within the "Atypia of undetermined significance/follicular lesion of undetermined significance" Bethesda category have significantly different rates of malignancy. Cancer Cytopathol. 2017;125(4):245-56.

20 Ahn SH, Kim SD, Jeong WJ. Comparison of risk of malignancy in a subgroup with atypia of undetermined significance/follicular lesion of undetermined significance: a meta-analysis. Head Neck. 2017;39(8):1699-710.

21 Iskandar ME, Bonomo G, Avadhani V, Persky M, Lucido D, Wang B, et al. Evidence for overestimation of the prevalence of malignancy in indeterminate thyroid nodules classified as Bethesda category III. Surgery. 2015 Mar;157(3):510-7.

22 Khalil AB, Dina R, Meeran K, Bakir AM, Naqvi S, Al Tikritti A, et al. Indeterminate thyroid nodules: a pragmatic approach. Eur Thyroid J. 2018;7(1):39-43.

23 Bray F, Ferlay J, Soerjomataram I, Siegel RL, Torre LA, Jemal A. Global cancer statistics 2018: GLOBOCAN estimates of incidence and mortality worldwide for 36 cancers in 185 countries. CA Cancer J Clin. 2018 Nov;68(6): 394-424.

24 La Vecchia C, Malvezzi M, Bosetti C, Garavello $\mathrm{W}$, Bertuccio $\mathrm{P}$, Levi F, et al. Thyroid cancermortalityand incidence: a global overview. Int J Cancer. 2015 May 1;136(9):218795.
25 Alseddeeqi E, Baharoon R, Mohamed R, Ghaith J, Al-Helali A, Ahmed LA. Thyroid malignancy among patients with thyroid nodules in the United Arab Emirates: a fiveyear retrospective tertiary centre analysis. Thyroid Res. 2018 Nov 30;11:17.

26 Vargas-Salas S, Martínez JR, Urra S, Domínguez JM, Mena N, Uslar T, et al. Genetic testing for indeterminate thyroid cytology: review and meta-analysis. Endocr Relat Cancer. 2018;25(3):R163-77.

27 Ozluk Y, Pehlivan E, Gulluoglu MG, Poyanli A, Salmaslioglu A, Colak N, et al. The use of the Bethesda terminology in thyroid fine-needle aspiration results in a lower rate of surgery for nonmalignant nodules: a report from a reference center in Turkey. Int J Surg Pathol. 2011 Dec;19(6):761-71.

28 Ho AS, Sarti EE, Jain KS, Wang H, Nixon IJ, Shaha AR, et al. Malignancy rate in thyroid nodules classified as Bethesda category III (AUS/FLUS). Thyroid. 2014 May;24(5):8329.

29 Lee KH, Shin JH, Oh YL, Hahn SY. Atypia of undetermined significance in thyroid fineneedle aspiration cytology: prediction of malignancy by US and comparison of methods for further management. Ann Surg Oncol. 2014 Jul;21(7):2326-31.

30 Valderrabano P, Khazai L, Thompson ZJ, Sharpe SC, Tarasova VD, Otto KJ, et al. Cancer risk associated with nuclear atypia in cytologically indeterminate thyroid nodules. a systematic review and metaanalysis. Thyroid. 2018 Feb;28(2):210-9.
31 Allen L, Al Afif A, Rigby MH, Bullock MJ, Trites J, Taylor SM, et al. The role of repeat fine needle aspiration in managing indeterminate thyroid nodules. J Otolaryngol Head Neck Surg. 2019;48(1):16.

32 VanderLaan PA, Marqusee E, Krane JF. Clinical outcome for atypia of undetermined significance in thyroid fine-needle aspirations: should repeated FNA be the preferred initial approach? Am J Clin Pathol. 2011;135(5): 770-5.

33 Eisa N, Khan A, Akhter M, Fensterwald M, Saleem S, Fananapazir G, et al. Both ultrasound features and nuclear atypia are associated with malignancy in thyroid nodules with atypia of undetermined significance. Ann Surg Oncol. 2018;25(13):3913-8.

34 Huhtamella R, Kholová I. Thyroid Bethesda category AUS/FLUS in our microscopes: three-year-experience and cyto-histological correlation. Cancers. 2019;11(11):1670.

35 Johnson DN, Cavallo AB, Uraizee I, Tanager K, Lastra RR, Antic T, et al. A proposal for separation of nuclear atypia and architectural atypia in Bethesda category III (AUS/FLUS) based on differing rates of thyroid malignancy. Am J Clin Pathol. 2018;151(1):86-94.

36 Hyeon J, Ahn S, Shin JH, Oh YL. The prediction of malignant risk in the category "atypia of undetermined significance/follicular lesion of undetermined significance" of the Bethesda System for Reporting Thyroid Cytopathology using subcategorization and BRAF mutation results. Cancer Cytopathol. 2014;122(5): $368-76$. 